\title{
Prevalence of Epstein-Barr Virus Genotypes in Pakistani Lymphoma Patients
}

\author{
Sadia Salahuddinn ${ }^{1,2}$, Jabbar Khan ${ }^{1}$, Joharia Azhar ${ }^{2}$, Christopher B. Whitehurst ${ }^{3}$, \\ Ishtiaq Qadri ${ }^{4}$, Julia Shackelford ${ }^{3}$, Joseph S. Pagano ${ }^{3}$, Dost Muhammad ${ }^{5}$, Kristy \\ L. Richards ${ }^{6}$
}

\begin{abstract}
The Epstein-Barr virus (EBV) is a herpesvirus infecting more than $90 \%$ of the human population. The tropism of EBV for B lymphocytes is evidenced in its association with many lymphoproliferative disorders. Different types of EBV (EBV-1 and EBV-2), classified on the basis of EBV nuclear antigen-2 (EBNA-2) genotyping, have been reported in benign and malignant pathologies, but there is almost no information about their frequency in the Pakistani population. The aim of this study was to determine the frequency and distribution of EBNA-2-based EBV genotypes in lymphoma patients. Genomic DNA was extracted from formalin-fixed paraffin embedded (FFPE) tissue samples obtained from 73 EBV-DNA-positive lymphoma patients. The $\beta$-globin gene was amplified to assess the presence and quality of cellular DNA from all samples. EBER-1 DNA was detected by PCR to confirm EBV presence in tissue samples. EBNA-1 mRNA relative quantification done by quantitative PCR substantiated EBNA-1 mRNA overexpression in $43.8 \%$ of EBV-positive cases in comparison to EBV-positive control cell line. EBNA-2 genotyping was done by nested PCR. Among typable samples, EBV-1 was found in $90.7 \%$ of samples while EBV-2 was present in $9.3 \%$ cases. These results show that EBV-1 was the most prevalent type in the lymphoma population of Pakistan. This epidemiology of EBV in Pakistani lymphoma patients represents an important first step in using EBV for prognosis and monitoring treatment response.
\end{abstract}

Keywords: Epstein-Barr Virus- Genotyping- Lymphoma- PCR- $\beta$-globin gene

Asian Pac J Cancer Prev, 19 (11), 3153-3159

\section{Introduction}

The Epstein-Barr virus is a herpesvirus that establishes a life-long persistent infection in over $90 \%$ of the human adult population worldwide. Its ability to immortalize human B lymphocytes in culture implicates EBV as a candidate transforming agent for $B$ lymphocytes with an important role in B-cell malignancies. EBV-associated malignancies have distinct patterns of latency on the basis of viral gene expression. EBV nuclear antigen 1 (EBNA1) is the only viral protein expressed in all forms of latency in EBV-associated tumors and proliferating cells (Gulley, 2001). EBNA1 expression has also been detected in healthy EBV-seropositive individuals, but the expression level in tumor cells is significantly higher than normal cells. EBNA1 localizes to the nucleus and binds with cellular DNA and is required for latency and transformation (Thompson and Kurzrock, 2004; Sample et al., 1990). Certain regions of the world are known to have endemic associations of EBV, for example, Burkitt lymphoma in Africa (Sample et al., 1990; Orem et al., 2007). Similarly, nasopharyngeal carcinoma in patients of South Asia is often caused by EBV-induced proliferation of epithelial cells (Orem et al., 2007; Tabuchi et al., 2011). In Hodgkin lymphoma (HL) the involvement of EBV varies greatly between ethnic groups and geographic locations (Tabuchi et al., 2011; Huang et al., 2011). EBV-positive HL appears to be less common in developed regions, with percentages between $20 \%$ and $50 \%$ in North America and Europe (Huang et al., 2011; Shenoy et al., 2011) and 57\% in China (Tabuchi et al., 2011; Weinreb et al., 1996), but with much higher incidence in countries with lower resources such as Mexico (66\%) (Zhou et al., 1993), Peru (94\%) (Shenoy et al., 2010) and Kenya (92\%) (Palma et al., 2013). A recent study reported $57 \% \mathrm{EBV}$ incidence in HL patients in Pakistan which is similar to that of the latter group of countries (Leoncini et al., 1996). There is very little known about EBV incidence and prevalence in the normal and

${ }^{1}$ Department of Biological Sciences, Gomal University, Dera Ismail Khan, ${ }^{5}$ Bannu Medical College, Bannu, KP, Pakistan, ${ }^{3}$ Lineberger Comprehensive Cancer Center, The University of North Carolina, Chapel Hill USA, ${ }^{6}$ Cornell University, Ithaca New York, United States, ${ }^{4}$ King Abdul Aziz University, Jeddah, ${ }^{2}$ Princess Nourah Bint Abdulrahman University, Riyadh, Saudi Arabia. *For Correspondence: sjabbarkhan@yahoo.com 
lymphoma populations of Pakistan. Further studies are required to confirm the pathological role of $\mathrm{EBV}$ in the Pakistani population, to determine the pattern of EBV association in different cancers, and to investigate other associated factors that may influence the development of cancer in Pakistan. EBV has been classified into different genotypes on the basis of divergent DNA sequences in the EBV-encoded nuclear antigens (EBNA) 2, 3A, 3B, and 3C (Weinreb et al., 1996). EBNA-2 based genotyping is most frequently used as it contains the most divergent locus among the latency genes. The predicted primary amino acid sequence of EBNA-2 between the two types is only $54 \%$ identical (Fatima et al., 2011). EBNA-2 is absolutely required for immortalization of infected $\mathrm{B}$ cells in vitro and in vivo. The biologic properties of these EBNA-2 types are different; EBV-1 more efficiently transforms and immortalizes infected B lymphocytes in vitro than EBV-2 (Fatima et al., 2011) yet the biological properties are nearly identical. The results of many serological studies have demonstrated that the distribution of EBV-1 versus EBV-2 has characteristically different frequencies in distinct geographic locations. EBV-1 is more prevalent in Western countries and also in Asia (Fatima et al., 2011; Tzellos and Farrell, 2012), whereas EBV-2 is more prevalent in central Africa, La Reunion and New Guinea (Quintanilla-Martinez et al., 1998; Ibrahim et al., 2010). The reason for this difference in distribution is not clear (uintanilla-Martinez et al., 1998).

\section{Objectives}

In Pakistan, the frequency and distribution of EBNA-2 genotypes in the cancer population is not yet well defined. This study hence examines the frequency of EBV and the distribution of EBNA-2 genotypes in the Pakistani lymphoma population.

\section{Materials and Methods}

\section{Patient Samples and cell line}

A total of 108 blocks of formalin fixed paraffin embedded (FFPE) lymphoma tissue were collected from different hospitals of Islamabad, Pakistan. It was a retrospective study and only B cell lymphoma samples were included. Samples were selected on the basis of convenient accessibility. Ethical approval and patient consent were obtained from living patients or patient's guardians during data collection.

Biopsies were taken from the brain, sub-mandibular, tonsil, thyroid, sub-auricle, nasopharynx, cervical, axillary, chest-wall, iliac fossa, abdominal, mesenteric, ovarian, testicular, intestinal, and epidural lesions from patients of both sexes with ages in the range of 6-83 years. Sample diagnosis was done with hematoxylineosin staining, and immunohistochemistry analysis with the help of corresponding antibodies in accordance to the instructions recommended by manufacturers. Nineteen specimens were excluded on the basis of lack of enough tissue or nucleic acid. Of the remaining of 89 DNA positive samples, 73 samples (53 non-Hodgkin lymphoma, 20 Hodgkin lymphoma) were selected for further study (Figure 1). KR4 (EBV-positive type III lymphoblastoid cell line), BL-41 (EBV Burkitt lymphoma derived cell line), and B95-8 (EBV-producing marmoset B lymphoblastoid cell line) were used during experiments.

\section{Genomic DNA Extraction}

DNA was extracted from the FFPE blocks using the xylene-ethanol method. A $20-\mu \mathrm{m}$ cut section of each block was deparaffinized by adding $1 \mathrm{ml}$ of xylene, agitated for $30 \mathrm{~min}$ at room temperature and then centrifuged at 13,000 $\mathrm{rpm}$ for $10 \mathrm{~min}$. The supernatant was removed carefully and the pellet was resuspended in $1 \mathrm{ml}$ fresh xylene. It was again agitated and centrifuged at 13,000 rpm for 10 min and supernatant was discarded. The pellet was washed twice with $100 \%$ ethanol followed by air-drying at $37^{\circ} \mathrm{C}$. Tissue digestion was done by adding $500 \mu \mathrm{g} / \mathrm{ml}$ of Proteinase $\mathrm{K}$ in $400 \mu \mathrm{l}$ of the tissue digestion buffer (100 mM Tris- HCl, pH 7.5 and Tween-20, 0.05\%) for 4 hours at $56^{\circ} \mathrm{C}$. It was then centrifuged at $13,000 \mathrm{rpm}$ for 10 min and the supernatant containing DNA was transferred to a clean tube. DNA from EBV-infected B95-8 cells was extracted using QIAamp DNA Mini Kit (Qiagen, UK) according to the manufacturer's instructions and was used as EBV-positive control in PCR reactions.

\section{Detection of $\beta$-globin by PCR}

PCR amplification of $\beta$-globin was used as an experimental control of cellular DNA. $\beta$-globin primers were used to detect the 130bp product (Table 1). Thirty $\mu 1$ reaction mix was prepared that consisted of 250-300 ng genomic DNA, 1x Taq reaction buffer containing $750 \mathrm{mM}$ Tris- $\mathrm{HCl}, 200 \mathrm{mM}(\mathrm{NH} 4)_{2} \mathrm{SO}_{4}, 0.1 \%$ (v/v) Tween $20,25 \mathrm{mM} \mathrm{MgCl}$ and $4 \mathrm{mM}$ dNTPs, 1.5 unit of Taq DNA polymerase, and 6 pmol each of forward and reverse primers. The reaction was carried out through 35 cycles that consisted of 30 seconds denaturation at $95^{\circ} \mathrm{C}$, 30 seconds annealing at $57^{\circ} \mathrm{C}$ and 30 seconds extension at $72^{\circ} \mathrm{C}$. Denaturation during the first cycle was done at $95^{\circ} \mathrm{C}$ for 5 minutes while the final extension was done at $72^{\circ} \mathrm{C}$ for 10 minutes. Amplified product (Figure 1) was electrophoresed on $2 \%$ agarose gel containing ethidium bromide for visualization.

\section{Detection of EBER-1 DNA by PCR}

The presence of EBV DNA was confirmed by amplifying an EBER-1 product of 140bp through specific primers (Table 1). For performing PCR reaction, 250 ng DNA, $400 \mu \mathrm{M}$ of each dNTP, 2 units of Taq DNA polymerase, $6 \mathrm{pmol}$ of each primer and $1 \mathrm{x}$ Taq reaction buffer were used in $30 \mu 1$ reaction volume. The reaction was carried out through 35 cycles that consisted of 30 seconds denaturation at $95^{\circ} \mathrm{C}, 30$ seconds annealing at $57^{\circ} \mathrm{C}$ and 30 seconds extension at $72^{\circ} \mathrm{C}$. Denaturation during the first cycle was done at $95^{\circ} \mathrm{C}$ for 5 minutes while the final extension was done at $72^{\circ} \mathrm{C}$ for 10 minutes.

\section{Nested-PCR Assay for EBNA-2 genotyping}

EBNA-2 gene amplification was carried out using the E2P1 (ATCC® B95.8 coordinates 48810 to 48829) and E2P2 (ATCC@ B95.8 coordinates 49058-49039) (Table 1) as previously described (17). For amplification of a $506 \mathrm{bp}$ fragment of the EBNA-2 gene, a PCR reaction 
was performed with 1x Taq buffer containing $200 \mathrm{mM}$ (NH4) $\mathrm{SO}_{4}$ with $0.1 \%(\mathrm{v} / \mathrm{v})$ Tween $20,25 \mathrm{mM} \mathrm{MgCl}_{2}, 750$ mM Tris-HCl, 200 ng DNA and 2mM dNTPs, 2 U of Taq polymerase DNA, and $20 \mu \mathrm{M} / \mu \mathrm{L}$ of each of the primers in $50 \mu \mathrm{l}$ reaction volume. The reaction was carried out through 35 cycles, consisting of 1 minute denaturation at $95^{\circ} \mathrm{C}, 1$ minute annealing at $64^{\circ} \mathrm{C}$ and 45 seconds extension at $72^{\circ} \mathrm{C}$. Denaturation during the first cycle was done at $95^{\circ} \mathrm{C}$ for 5 minutes while the final extension was done at $72^{\circ} \mathrm{C}$ for 7 minutes. The second PCR was performed using the amplified product of the first round PCR, under the same reaction and cycling conditions but with different primers, namely the EBV-1 and EBV-2 type specific inner primers: AP1 and AP2 for EBV-1, and BP1 and BP2 for EBV-2 (Table 1) (Durmaz et al., 1998). The EBV-1 and EBV-2 amplicons produced fragments of 497 and $150 \mathrm{bp}$, respectively (Figure 1). The PCR products were visualized with $2 \%$ agarose gel electrophoresis containing ethidium bromide.

\section{Quantitative PCR of EBNA-1 transcripts}

Relative quantification was performed to detect the EBNA-1 transcript levels. Total RNA $(1 \mu \mathrm{g})$ was reversely transcribed using high-capacity cDNA Reverse Transcription Kit (Applied Biosystems) according to the manufacturer's instructions. EBNA-1 gene expression analysis was performed using $\mathrm{iTaq}^{\mathrm{TM}}$
Universal SYBR ${ }^{\circledR}$ Green Supermix (Bio-Rad, USA) according to manufacturer protocol. GAPDH was used as the reference gene (Table 1). Thermocycling were performed using Applied Biosystems 7900 real-time PCR system. All the samples were run in triplicate. EBV- BL41, template-control, and reverse transcriptase controls were run to verify the purity of the sample. Data were analyzed using the $\Delta \Delta \mathrm{Ct}$ method where target gene expression was normalized to the housekeeping gene by taking the difference between $\mathrm{Ct}$ values for the target gene and reference gene $(\Delta \mathrm{Ct})$. This value was then compared to that of the normalized control sample $(\Delta \Delta \mathrm{Ct})$. The fold change was determined using the formula: $2^{-\Delta \Delta \mathrm{Ct}}$. Data were analyzed and compared to GAPDH expression, and then determined relative to KR-4 cells.

\section{Results}

We address the issue of prevalence of EBV in 73 lymphoma patients. Eighty-nine samples were selected out of a total of 108 samples on the basis of the presence of amplifiable DNA $(n=89)$ and EBV positivity $(n=73)$. The most common sites of the tumor were cervical lymph node followed by axillary and abdominal lymph nodes. Although the sample collection from different institutes was impartial of age and gender, a higher incidence of lymphoma was observed with increase in age in both

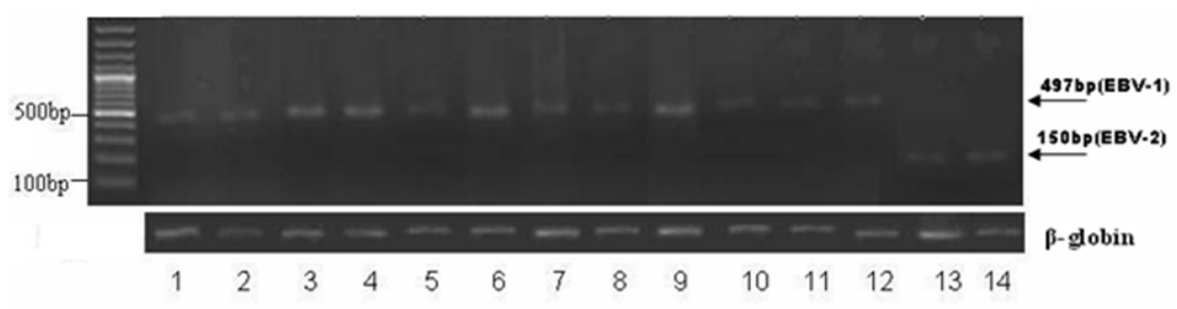

Figure 1. Characterization of EBV in FFPE Tissue Samples of Lymphoma Patients; Lanes 1 to 12 with 497 bp band size, indicated with an arrow, show amplified products of EBV-1; Lanes 13 and 14 with 150 bp band size, indicated by the arrow, show amplified products of EBV-2 DNA; The $\beta$-globin gene with the amplified product of 130 bp has been used as an experimental control, and $\mathrm{M}$ is the marker.

Table 1. Primers Used for PCR Amplification

\begin{tabular}{|c|c|c|c|}
\hline Primer & Sequence 5'-3' & Target Gene & Amplimer Length (bp) \\
\hline BG-F & GTGCTCGGTGCCTTTAGTGA & $\beta$-globin & 130 \\
\hline BG-R & CAGGGTGAGTCTATGGGACG & & \\
\hline EBER-1F & AGGACCTACGCTGCCCTAGA & EBER-1 & 140 \\
\hline EBER-1R & AAAACATGCGGACCACCAGCTGG & & \\
\hline E2P1 & AGGGATGCCTGGACACAAGA & EBNA-2 & 597 \\
\hline E2P2 & TGGTGCTGCTGGTGGTGGCAAT & & \\
\hline AP1 & TCTTGATAGGGATCCGCTAGGATA & EBNA-2 Type-1 & 497 \\
\hline AP2 & ACCGTGGTTCTGGACTATCTGGATC & & \\
\hline BP1 & CATGGTAGCCTTAGGACATA & EBNA-2 Type-2 & 150 \\
\hline BP2 & AGACTTAGTTGATGCCCTAG & & \\
\hline EBNA-1F & TACAGGACCTGGAAATGGCC & EBNA-1 & 150 \\
\hline EBNA-1R & TCTTTGAGGTCCACTGCCG & & \\
\hline GAPDH-F & TCATCAGCAATGCCTCCT & GAPDH & 138 \\
\hline GAPDH-R & AGGGGCCATCCACAGTCTTC & & \\
\hline
\end{tabular}


Table 2. Incidence of Different Types of Lymphoma and EBV Genotypes by Age

\begin{tabular}{lccccc}
\hline Age Group & \multicolumn{2}{c}{ Histology Groups } & & \\
& Hodgkin Lymphoma & Non-Hodgkin Lymphoma & EBV-1 & EBV-2 & Undetected \\
\hline $6-30$ & 7 & 16 & 17 & 2 & 4 \\
$31-60$ & 13 & 25 & 32 & 4 & 2 \\
$61-83$ & 0 & 12 & 10 & 0 & 2 \\
Total & 20 & 53 & 59 & 6 & 8 \\
\hline
\end{tabular}

Table 3. EBV Genotype Distribution in Different Types of Lymphomas

\begin{tabular}{lcccc}
\hline Histology & EBV-1 $(\mathrm{n}=59)$ & EBV-2 $(\mathrm{n}=6)$ & Undetected $(\mathrm{n}=8)$ & Total \\
\hline Hodgkin Lymphoma & 6 & & 1 & 8 \\
Nodular Sclerosis & 7 & 1 & 0 & 8 \\
Mixed Cellularity & 4 & 1 & 0 & 4 \\
Lymphocyte Rich & & & 5 & 22 \\
Non-Hodgkin Lymphoma & 16 & 1 & 0 & 1 \\
Diffuse Large B-cell & 0 & 1 & 1 & 8 \\
Anaplastic Large Cell & 7 & 0 & 0 & 2 \\
Small Lymphocytic & 2 & 0 & 0 & 5 \\
Lymphoblastic & 5 & 0 & & 3 \\
Burkitt & 3 & 2 & 1 & 12 \\
MALToma & 9 & & & \\
NHL (unclassified) & & & 5 \\
\hline
\end{tabular}

sexes (Table 2).

\section{Detection of EBV in Lymphoma Tissue}

All the 53 Non-Hodgkin Lymphoma and 20 Hodgkin Lymphoma patients were characterized for incidence of EBV (Figure 1, Table 2). Their ages were in the range of 6 years to 83 years. Fifty-nine $(81 \%)$ out of 73 were having EBV-1 infection while only $6(8.0 \%)$ patients had EBV-2 infection (Table 2). The highest numbers of patients infected with EBV were found in the age group of 31-60 years (Table 1). Eight (10.5\%) patients remained undetected for EBV (Table 2 and 3).

We also determined EBNA-1 mRNA expression in
$76 \%$ of samples in relation to EBV KR4 cell line through qRT-PCR (Figure 3, Suppl. Table). GAPDH was used as the reference gene. Samples with a $\mathrm{Ct}$ value above 35 were omitted from the analysis and considered negative. The observed EBNA-1 expression within samples varied up to 2-fold between the samples (Figure 3). By estimating significance using lack of overlap of the standard error bars, 32 out of 73 (43.8\%) of cases over-expressed EBNA-1 relative to levels in the EBV-positive cell line KR-4. The averages of EBNA-1 relative fold change in Hodgkin lymphomas and Burkitt lymphomas samples were higher than other disease samples (Supplementary Table). However, only the difference in Burkitt lymphoma

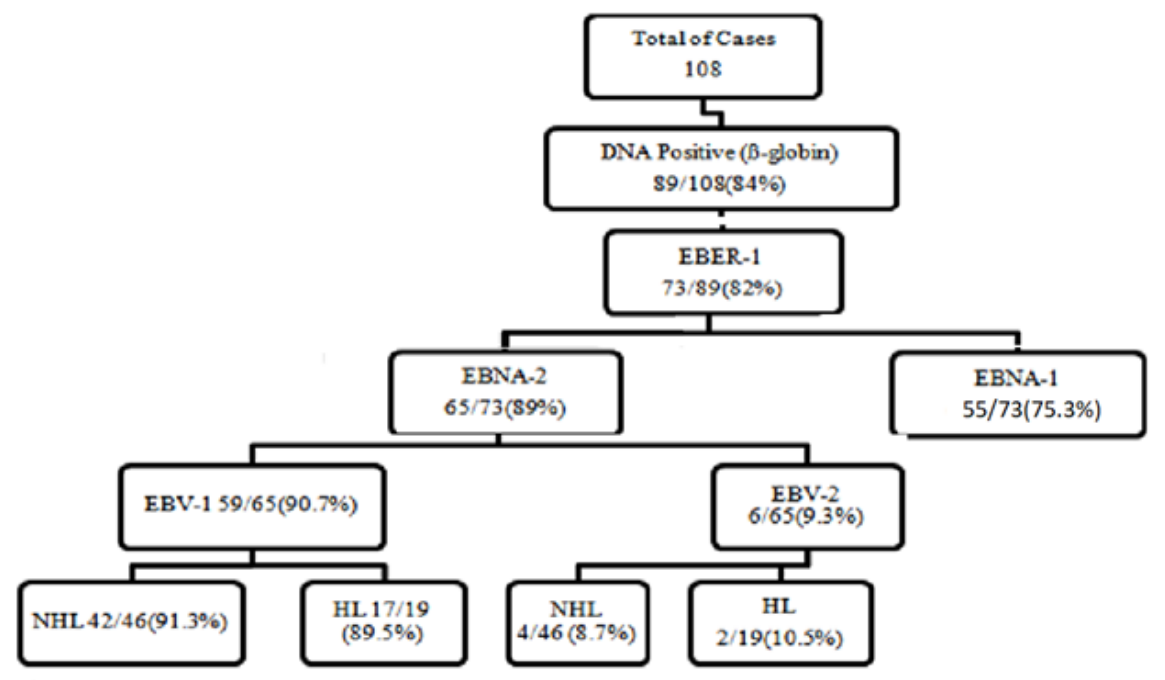

Figure 2. Distribution of the EBV-Positive Cases Detected by EBV DNA (EBER-1), EBNA-1 RNA, and EBNA2A (EBV-1), and EBNA2B (EBV-2) Genotyping. Abbreviation: HL Hodgkin lymphoma, NHL Non-Hodgkin lymphoma 


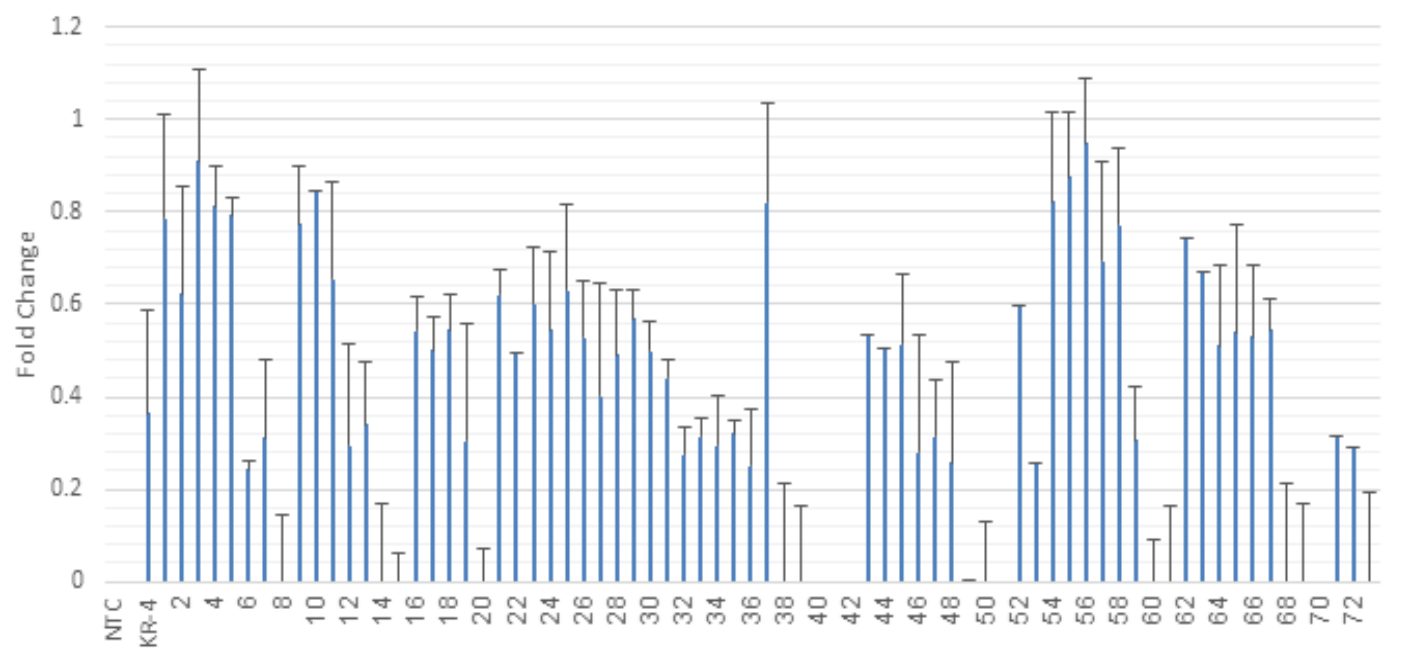

Figure 2. Expression of EBNA-1 mRNA in Representative FFPE Lymphoma Samples, The expression levels of lymphoma samples are shown in comparison to EBV-positive KR-4 cells, EBV-negative BL-41 cells and non-template control (NTC).

samples was statistically significant $(\mathrm{p}=0.024)$.

\section{EBNA-2 Genotyping}

Of the total 73 positive samples, EBNA-2A (EBV-1) was detected in $42(91.3 \%)$ out of 46 of NHL samples and in $17(89.5 \%)$ out of 19 of HL samples. Compared to EBNA-2A (EBV-1, EBNA-2B (EBV-2) was found only in $4(8.7 \%)$ out 46 NHL samples and in $2(10.5 \%)$ cases out of 19 HL samples (Table 3). Mixed genotypes were not detected in any lymphoma sample. EBV-1 genotype was the most prevalent $(90.7 \%)$ EBV infection in all age groups of both HL and NHL patients (Table 2 and 3).

Statistical analyses showed no significant correlation between EBNA-2 genotypes and histology HL vs. NHL $(p=0.82)$.

\section{Discussion}

We attempted to assess EBV frequencies and genotypes in B-cell lymphoma patients of Pakistan, as knowledge of EBV prevalence and its association in Pakistani lymphoma patients is largely unknown (. Fatima et al., 2011; Ishtiaq et al., 2013; Noorali et al., 2004). We determined the prevalence of EBV in tumor tissues at the DNA and RNA level by PCR. EBER-1 is the most abundant viral transcript in latently infected cells (Ngan et al., 2001) and therefore useful as a marker for the detection of latent EBV infection even with a limited quantity of nucleic acid from FFPE tissues. We were unable to compare our results with EBER-RNA in situ hybridization, which is the standard for pathogenic EBV diagnosis in tumor cells, due to unavailability of the technique at our institute. In this study, EBER-1 DNA was detected in $82 \%$ of lymphoma samples with conventional PCR, compared to previous studies wherein EBV DNA was detected in $31-82 \%$ tumor samples through PCR technique (Kanakry et al., 2007; Tisi et al., 2015). As we chose a different marker to confirm the presence of the virus at the DNA level, we cannot reliably relate our results to those studies.

EBV RNA was detected in lymphoma samples by detecting increased expression of EBNA-1. Semi-quantitative detection of EBNA-1 mRNA or its viral load in lymphoma patients has been suggested as a useful diagnostic marker and a predictive prognostic factor (Brink et al., 2001). We found the frequency and expression of EBNA-1 mRNA in $75.3 \%$ of lymphoma cases which are in accordance previous reports on Western countries where EBNA-1 mRNA was detected in 50\%$75 \%$ of lymphoma patients (Bell et al., 2006). However, EBNA-1 mRNA expression in Pakistani lymphomas was less frequent compared to Uganda and Hong Kong populations, where EBNA-1 expression was found in almost $90 \%$ of tumor tissues (Tierney et al., 2015). Although the simplicity of PCR favors its adoption as a first-line method for EBV-positive lymphoma diagnosis, its high sensitivity may produce false positive results due to detection of EBV-positive memory cells and/or non-tumor, bystander lymphocytes. However, if strictly standardized, quantitative PCR methods can be adopted for detection as the levels from EBV-positive memory cells in healthy seropositive individuals is less than the EBV viral load in tumor cells (Brady et al., 2007). This study attempted to find an association of EBV genotypes with specific disease pathogenesis in the Pakistani population, in particular with respect to frequency and distribution of EBNA-2- based EBV genotypes in lymphoma patients. In our study, eight lymphoma samples (11\%) were non-typable for EBNA-2 gene. The inability to determine EBV type in eight lymphoma samples was surprising since they were positive for EBV nucleic acid. It is suggested that the primers were unable to bind on account of sequence variation in EBNA-2. Sequencing EBNA-2 in the Pakistani population will be required to identify possible polymorphisms in the EBNA-2 region. We found an EBV-1 genotype relative frequency of $91 \%$ in Pakistani lymphoma patients, which is noticeably higher than in Caucasian populations, of up to $74 \%$ (Correa et al., 2004; Glaser et al., 2008). However, these statistics are more comparable to those from other Asian countries, which also show a stronger predominance 
of EBV-1 prevalence at about $85 \%$ ( Tiwawech et al., 2008; Trimèche et al., 2007). Due to the low frequency of EBV-2 in our population, we could not determine differences in EBV genotype associations for different types of lymphomas; however, this study established that EBV-1 was the predominant genotype in all kinds of lymphomas. Likewise, we observed no differences in EBV genotype in male vs. female patients, or by age.

The presence of EBV in malignancies offers the prospect for therapeutic interventions targeting virusencoded proteins. Currently, EBV status is not routinely determined in lymphoma patients in Pakistan. On the basis of the higher frequency of EBV antigen reported during the study, it is strongly suggested that determination EBV in all lymphomas at the time of diagnosis should be done as this could help clinicians develop disease monitoring by EBV levels or a virus-targeted therapeutic approach in future.

In conclusion, EBNA-1 mRNA expression occurrence, comparable to Western countries. EBV-1 is the most prevalent genotype in Pakistani lymphoma patients irrespective of sex and age.

\section{Statistical Analysis}

Correlation analyses between EBV genotypes and histology were performed by calculating Pearson correlation coefficient and Chi-square test. The analysis of gene expression data was performed by Student unpaired t-test. $P$ values of $>0.05$ were considered not significant.

\section{Conflict of Interest}

The authors, regarding the publication of the article, have no conflict of interest.

\section{Acknowledgments}

We thank Dr. Sharof Tugizov (University of California, San Francisco) for providing B95-8 cells. This work was supported by grants from the NCI (CA163217 to JSP) and supplemental funding from the NCI to UNC Lineberger Comprehensive Cancer Center and CFAR to JSP. KLR and SS were supported by a grant from the NCI (R01-CA185372 to KLR).

\section{References}

Bell AI K, Groves GL, Kelly D, et al (2006). Analysis of Epstein-Barr virus latent gene expression in endemic Burkitt's lymphoma and nasopharyngeal carcinoma tumor cells by using quantitative real-time PCR assays. $J$ Gen Virol, 87, 2885-90.

Brady GG, MacArthur D, Farrell P (2007). Epstein-Barr virus and Burkitt lymphoma. J Clin Pathol, 60, 1397-1402.

Brink AC, Meijer J, Nicholls J, Middeldorp A, Van den B (2001). Activity of the EBNA1 promoter associated with lytic replication in Epstein-Barr virus-associated disorders. $\mathrm{Mol}$ Pathol, 54, 98.

Correa RM, Fellner MD, Alonio LV, et al (2004). Epstein-Barr virus $(\mathrm{EBV})$ in healthy carriers: Distribution of genotypes and 30 bp deletion in latent membrane protein-1 (LMP-1) oncogene. J Med Virol, 73, 583-8.

Durmaz R, Aydin A, Köroglu M, et al (1998). Detection and genotyping of Epstein-Barr virus by polymerase chain reaction in tissues obtained from cases with Hodgkin's disease in Turkey. Acta Virol, 42, 375-81.

Fatima SR, Ahmed D, Ahmed A (2011). Hodgkin lymphoma in Pakistan: an analysis of subtypes and their correlation with Epstein-Barr virus. Asian Pac J Cancer Prev, 12, 1385-8.

Glaser SL, Gulley ML, Clarke CA, et al (2008). Racial/ethnic variation in EBV-positive classical Hodgkin lymphoma in California populations. Int J Cancer, 123, 1499-1507.

Gulley ML (2001). Molecular diagnosis of Epstein-Barr virus-related diseases. J Mol Diagn, 3, 1-10.

Heslop HE (2005). Biology and treatment of Epstein-Barr virus-associated non-Hodgkin lymphomas. ASH Hematol Edu Prog, 2005, 260-6.

Huang XI, Nolte Z, Gao H, et al (2011). Epidemiology of classical Hodgkin lymphoma and its association with Epstein Barr virus in Northern China. PLoS One, 6, e21152.

Ibrahim HA, Menasce LP, Pomplun S, et al (2010). Epstein-Barr virus (EBV) genotypes among human immunodeficiency virus (HIV)-related B-cell Lymphomas and B-cell post-transplant lymphoproliferative disorders (B-PTLD) late-onset lymphomas, especially in the HIV setting, are associated with type-B-EBV. Eur J Haematol, 85, 227-30.

Ishtiaq SU, Hassan S, Mushtaq H, Akhtar N (2013). Determination of frequency of Epstein-Barr virus in NonHodgkin Lymphomas using EBV latent membrane protein 1 (EBV-LMP1) immunohistochemical staining. Asian Pac J Cancer Prev, 14, 3963-7.

Kanakry JA, Hegde AM, Durand CM, et al (2017). The clinical significance of EBV DNA in the plasma and peripheral blood mononuclear cells of patients with or without EBV diseases. Blood, 127, 2007-10.

Leoncini L, Spina D, Nyongo A, et al (1996). Neoplastic cells of Hodgkin's disease show differences in EBV expression between Kenya and Italy. Int J Cancer, 65, 781-4.

Mansoor A, Stevenson MS, Li R, et al (1997). Prevalence of Epstein-Barr viral sequences and EBV LMP1 oncogene deletions in Burkitt's lymphoma from Pakistan: epidemiological correlations. Hum Pathol, 28, 283-8.

Ngan RK, Lau W, Yip TT, et al (2001). Remarkable application of serum EBV EBER-1 in monitoring response of nasopharyngeal cancer patients to salvage chemotherapy. Ann N Y Acad Sci, 945, 73-9.

Noorali S, Pervez S, Yaqoob N, et al (2004). Prevalence and characterization of anaplastic large cell lymphoma and its association with Epstein-Barr virus in Pakistani patients. Pathol Res Pract, 200, 669-79.

Orem J, Mbidde EK, Lambert B, de SanjoseS, Weiderpass E (2007). Burkitt's lymphoma in Africa, a review of the epidemiology and etiology. Afr Health Sci, 7, 56-60.

Ouedraogo DE, Bollore K, Viljoen J, et al (2014). Comparison of EBV DNA viral load in whole blood, plasma, B-cells and B-cell culture supernatant. J Med Virol, 86, 851-6.

Palma I, Sánchez AE, Jiménez-Hernández E, et al (2013). Detection of Epstein-Barr virus and genotyping based on EBNA2 protein in Mexican patients with Hodgkin lymphoma: a comparative study in children and adults. Clin Lymphoma Myeloma Leuk, 13, 66-272.

Quintanilla-Martinez L, Lome-Maldonado C, Schwarzmann F, et al (1998). Post-transplantation lymphoproliferative disorders in Mexico: an aggressive clonal disease associated with Epstein-Barr virus type A. Mod Pathol, 11, 200-8.

Sample J, Young L, Martin B, et al (1990). Epstein-Barr virus types 1 and 2 differ in their EBNA-3A, EBNA-3B, and EBNA-3C genes. $J$ Virol, 64, 4084-92.

Shenoy P, Maggioncalda M, Malik N, Flowers CR (2010). Incidence patterns and outcomes for Hodgkin lymphoma 
patients in the United States. Adv Hematol, 10, 1-11.

Tabuchi K, Nakayama M, Nishimura B, Hayashi K, Hara A (2011). Early detection of nasopharyngeal carcinoma. Int J Otolaryngol, 2011, 1155-60.

Thompson MP, Kurzrock R (2004). Epstein-Barr virus and cancer. Clin Cancer Res, 10, 803-21.

Tierney RJ, Shannon-Lowe CD, Fitzsimmons L, Bell AI, Rowe M (2015), Unexpected patterns of Epstein-Barr virus transcription revealed by a High throughput PCR array for absolute quantification of viral mRNA. Virology, 474, 117-30.

Tisi MC, Cupelli E, Santangelo R,et al (2015). Whole blood EBV-DNA predicts outcome in diffuse large B-cell lymphoma. Leukemia Lymphoma, 57, 628-34.

Tiwawech D, Srivatanakul P, Karalak A, Ishida T (2008). Association between EBNA2 and LMP1 subtypes of Epstein-Barr virus and nasopharyngeal carcinoma in Thais. $J$ Clin Virol, 42, 1-6.

Trimèche M, Bonnet C, Korbi S, Boniver J, Leval LD (2007). Association between Epstein-Barr virus and Hodgkin's lymphoma in Belgium: a pathological and virological study," Leukemia Lymphoma, 48, 1323-31.

Tzellos S, Farrell PJ (2012). Epstein-Barr virus sequence variation biology and disease. Pathogens, 1, 156-74.

Weinreb M, Day P, Niggli F, et al (1996). The role of Epstein-Barr virus in Hodgkin's disease from different geographical areas. Arch Dis Child, 74, 27-31.

Zhou XG, Hamilton-Dutoit SL, Pallesen G, Yan QH (1993). The association between Epstein Barr virus and Chinese Hodgkin's disease. Int J Cancer, 55, 359-63.

\section{c) (7) (5)}

This work is licensed under a Creative Commons AttributionNon Commercial 4.0 International License. 